\title{
Standard Written Academic English: A Critical Appraisal
}

\author{
Laura (Violeta) Colombo
}

\begin{abstract}
Science today is mainly communicated through standard written academic English (SWAE). In this paper, I apply the postulations of Gramsci, Bourdieu and Canagarajah to show how domination structures are reproduced in scientific communication worldwide. I argue that these structures do not allow nondominant epistemologies and ways of producing and communicating science to participate in the international arena. I apply a critical lens to interpret each one of the terms present in SWAE. I propose that a critical appraisal of each one of these terms is the first step towards a more democratic conceptualization of science communication where the standards are not only seen as a means of innocuous communication but also as ideologically charged fictitious universals. It is my claim that understanding the arbitrary nature of these universals and the influence that language has on knowledge construction will give space to nondominant ways of producing and communicating knowledge.
\end{abstract}

\section{Standard Written Academic English: A Critical Appraisal}

It is widely known that in today's world science is mainly communicated through writing. Writing plays a major role in academic communities as a way of producing and legitimizing knowledge (Bourdieu, 1986). In addition, many scholars agree that English has become the "language of science" (Canagarajah, 2002b; Curry \& Lillis, 2004; Čmejrková, 1996; Hyland, 2006, Martín-Martín, 2003; Mauranen, 1996; Pennycook, 2001; Reichelt, 2001; Swales \& Feak, 1994; among others) at an international level. Therefore, in order to participate in the international sphere, scholars are expected to use standard written academic English (SWAE ${ }^{5}$ ). If we take into account that SWAE is the main means through which academic discourse is spread, not only nationally but also internationally, the analysis of SWAE becomes imperative to acknowledge the reproduction of social inequalities. This paper proposes a critical appraisal of what the term SWAE implies and how each one of its components and the meanings tied to them are rooted in domination structures present in the current ways of communicating science.

\footnotetext{
5 I would like to apologize to the reader for not following in this paper the same order in which each word appears in the acronym. However, clarity in the presentation of my argument seemed to be more important in this case.
} 


\section{Method}

In this paper I offer a critical analysis of what the use of SWAE implies. In order to do this, I first apply Gramsci's postulations to analyze the hegemonic prominence of writing among other communicative means for academic and scientific 6 communication. Second, I utilize Bourdieu's ideas to explore the term academic and to analyze the structures of domination that are present in the national and international scientific fields due to the use of SWAE. Third, I draw on Canagarajah's claims to consider what is standard in SWAE and how this is related to a monolithic view of language. Finally, I propose that for SWAE to allow a more democratic participation in the international scientific field all these issues should be acknowledged.

\section{Why written academic language?}

In this section I apply the framework offered by Antonio Gramsci to propose that writing is a major component in the current hegemonic modes of communication of science and knowledge. I first briefly explain the concepts of structure and superstructure in economic systems, according to traditional Marxism. Second, I present Gramsci's claims about the importance of the superstructure. Finally, I explain the role of writing in the current hegemonic modes of communication of science.

In today's society, scientific activity is mostly communicated through written language (Ventola \& Mauranen, 1996). Writing plays a major role not only as a means for communicating science but also as an artifact that defines worldwide scientific work as such (Buta \& Sued, 2005). Scientific work is mainly situated in academic institutions which, in Marxist terms, are part of the superstructure, the ideological terrain.

In traditional Marxism, economic systems could be defined as having a base or structure, and a superstructure. The base is constituted by the material conditions of a specific time: forces of production, relations of production and the modes of production of a specific economic system. These are the elements on which Karl Marx mainly centered his economic analysis. On the other hand, the superstructure is defined as false ideology or "mere illusions" (Forgacs, 1988, p. 196) that endorse the interests of the dominant group. In traditional Marxism, therefore, the base (or structure) determines the superstructure. Figure 1 illustrates this.

\footnotetext{
${ }^{6}$ In this paper I use the words "science" and "scientific" not only to refer to what is related to the commonly called "sciences" in US academia. Because it goes beyond the focus of this paper, I leave aside the dichotomy between sciences and humanities, and include both in the categories of "science" and "scientific."
} 


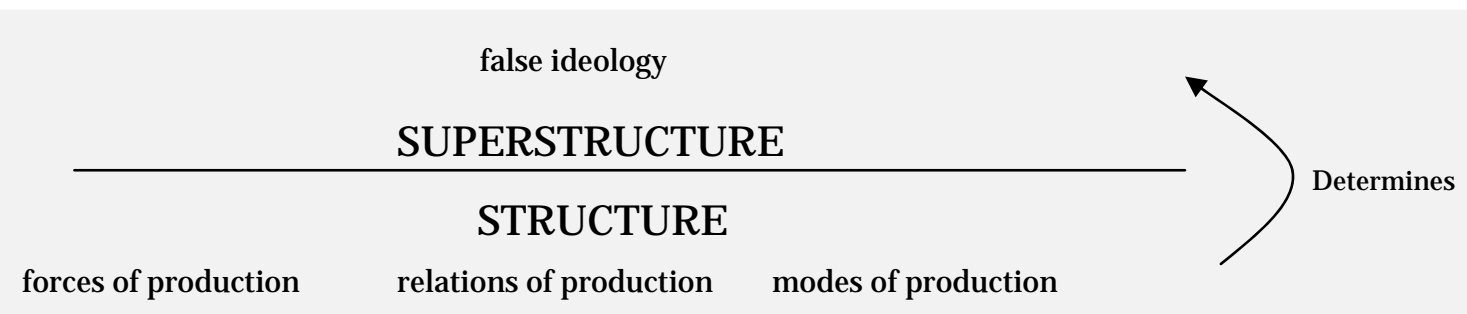

Figure 1. Elements of and relationships between structure and superstructure in traditional Marxism

Contrary to traditional Marxists, Gramsci saw the superstructure as a much more complex phenomenon, as more than an "immediate expression of the structure" (Forgacs, 1988, p. 190). In search of an answer and a practical application that would promote social change, the author opened new directions for Marxist discussions by claiming that base and superstructure are interconnected, although not deterministically. According to Forgacs (1988), Gramsci maintained that there existed "a reciprocity between structure and superstructures, a reciprocity which is nothing other than the real dialectical process" (Forgacs, 1988, p. 193). Therefore, not only do changes in the base determine changes in the superstructure, but changes in the "ideological terrain" (Forgacs, 1988, p. 190) can also generate changes in the structure.

In his analysis of the "sphere of the complex superstructure" (Forgacs, 1988, p. 189), Gramsci further explores the "ideological terrain," frequently forgotten by previous thinkers, and he classifies institutions as either coercive or noncoercive. Coercive institutions are associated with what the author names "political society" and domination, since they exercise direct coercion on individuals. Noncoercive institutions are related to the civil society and are associated with the concept of hegemony. While hegemony and domination are both forms of control, domination is the "direct physical coercion by police and armed forces" and hegemony is the "ideological control and more crucially, consent" (Burke, 1999, online). This is the ideological control of the dominant class along with the consent of the dominated class. According to Burke (1999), hegemony for Gramsci "meant the permeation throughout society of an entire system of values, attitudes, beliefs and morality that has the effect of supporting the status quo in power relations. Hegemony in this sense might be defined as an 'organising principle' that is diffused by the process of socialisation into every area of daily life" (Burke, 1999, online). These principles go unnoticed, and thus reinforce those discourses that keep in power those already in power. Figure 2 illustrates Gramsci's stand on the relationship between structure and superstructure and the different elements that compose both of them. 


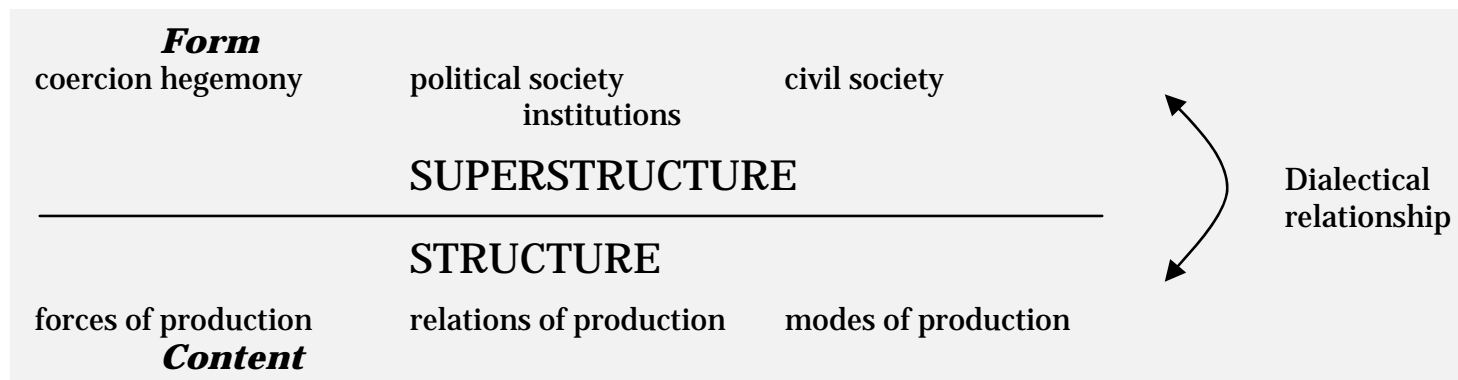

Figure 2. Elements of and relationships between structure and superstructure in Gramci's writings

As part of the superstructure, academic institutions are noncoercive institutions that contribute to the hegemony of the dominant groups in society. In Gramsci's terms, the superstructure has a dialectical relationship with the structural conditions. The structural conditions in capitalism, then, define the specific modes of production of science and knowledge in a capitalist society. Current structural conditions of scientific work in academia are highly linked to legitimized modes of scientific production, within which writing plays a major role in validating research findings when these are communicated to the scientific community.

The current legitimized modes of scientific production, according to Canagarajah (2002b), are still linked to the tradition of scientific positivism despite the appearance of recent orientations that link writing with knowledge construction (i.e., a post-Enlightment orientation to knowledge construction). In the scientific positivist tradition, "knowledge is supposed to precede the writing of it in textsand therefore stand free of factors of language and communication" (Canagarajah, 2002 b, p. 59). This separation of the context of "production" and communication of knowledge leads to a reification of writing that sets the publication of scientific articles (with their exchange and use values) as an imperative for being recognized as an expert in any worldwide scientific field. It is along this line that Buta and Sued (2005) affirm that "la función del artículo científico ... consiste en algo más que la comunicación de un nuevo conocimiento. Originada en los reclamos por la propiedad intelectual de las contribuciones, se construye además como instrumento de medición de la productividad del científico como trabajador, índice de pertenencia a un determinado campo científico"7 (p. 3).

Therefore, despite the variations that may exist in local material conditions influencing the production of knowledge, researchers worldwide feel the imperative to publish. This imperative reinforces those standardized modes of labor imposed by the publication market and further reinforced by world-wide gate-keeping

\footnotetext{
7 "The function of scientific articles ... goes beyond the communication of new knowledge. With its origin in the intellectual claim implied in [Originating in claims on the intellectual property of] the contributions, [this function] is also constituted as an instrument to measure the productivity of the researcher as worker, a measure of membership in a specific scientific field." (The translation is mine).
} 
mechanisms (for a more detailed discussion see Curry \& Lillis, 2004) that endorse a manufactured consent held by the hegemonic power of the ruling class in capitalism.

The materialization of this hegemonic power in science can be found in the prevalence of writing as the preferred and legitimized mode of communicating science worldwide. It is in this sense that the relationship between structure and superstructure reinforces the hegemony in the economic system, since writing as the legitimized mode of communication of science reinforces and defines the scientific activity as such following the tradition of scientific positivism.

Nevertheless, if we take into account Gramsci's stance on the reciprocal character of the relationship between structure and superstructure, there is a greater possibility of social change if the forces of change operate not only on the structure, but also on the superstructure. Therefore, change can be generated by a "war of position" or by a "war of movement." The war of position is held in the terrain of the civil society, which is "a site of consent, hegemony, direction," while the war of movement is "a frontal assault on the state" or political society, "which is a site of coercion, dictatorship, domination" (Forgacs, 1988, p. 224). Gramsci, then, envisions a real opportunity for change associated not only with material conditions but also with an "ideological struggle" (Forgacs, 1988, p. 223). This ideological struggle is the struggle for counter-hegemony that is waged through the war of position in which hegemony is challenged and there is a struggle to forge new consent around counter-hegemonic ideas. The following figure shows in bold those areas where intellectuals could play a major role and start acting as forces for social change.

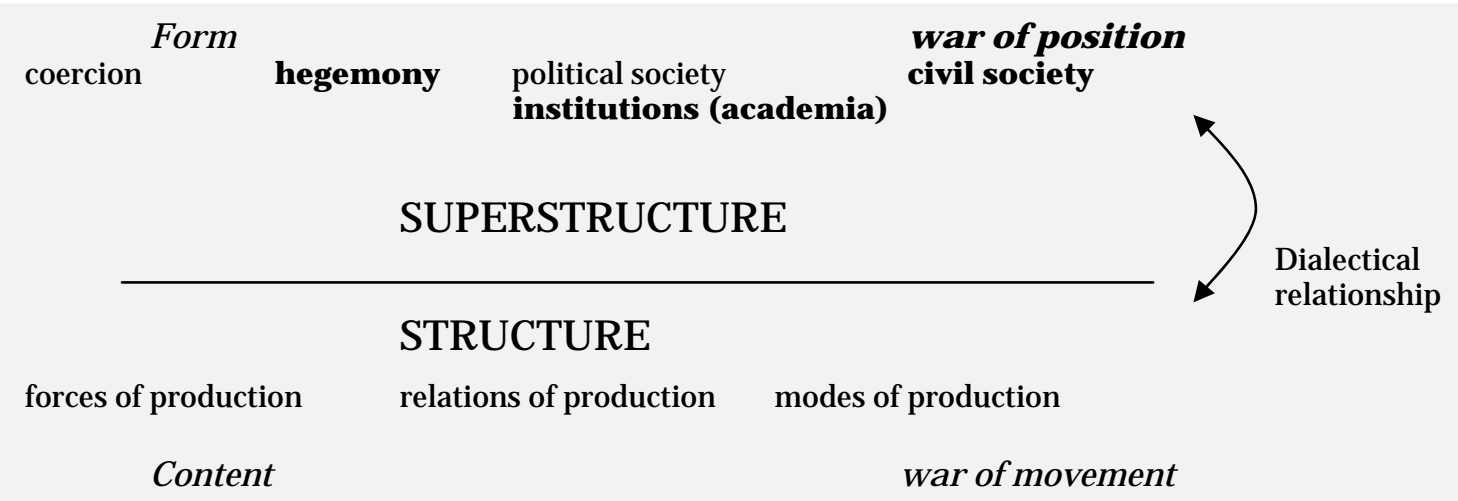

Figure 3. Positioning of the counter-hegemonic discourses in the superstructure (see bolded words)

In the war of position, then, counter-hegemonic discourses would be defying the dominant hegemonic discourses in different areas in the superstructure. In the case of academic writing, a war of position against the absolute prominence of written language to communicate science could start in the territory of academic institutions. This counter-hegemonic movement could propose other ways of communicating science that do not rely heavily on written language, but that also draw on other communicative means such as oral or visual communication. 
For example, Canagarajah (1996) reports that in nondominant academic cultures the communication of science "is more significantly taking place in face-toface oral interactions rather than in print" (p. 458). As will be shown in following sections, these differences in the ways in which knowledge is communicated also influence the way knowledge is produced. Wysocki (2004) also acknowledges how the visual is still pretty much absent "in the circulation of academic and other 'serious' writing" (p. 14). The author proposes that it should be acknowledged how the "different technologies of production-of writing, of photograph, and so onhave the status and position-building weights and possibilities they do because of how they fit within the broad but contingent material practices and structures in which we all live" (p. 23). In this way, both authors voice the fact that the means and materiality through which knowledge is communicated are not neutral; rather they are related to social practices and material realities present in academia.

If different modes were more frequently used for communicating science (for example, the oral and visual modes mentioned), they would permeate the superstructure, and along with them, different epistemologies and methodologies ${ }^{8}$ (born in places where the material conditions for the production of knowledge step aside from the dominant capitalist paradigm) would start having validity in the academic field. In addition, new modes of communicating science could appear thanks to the aid of current technological advances. For example, an oral modality supported by computer-mediated communication could open the door to a more dialogical style since the deferred nature of writing would be replaced by synchronic communication.

Regardless of the materialization that these new modes take (oral, visual, face-to-face, computer-mediated, etc.), what they share in common is that they need to gain space in academia in order to constitute counter-hegemonic forces that lead to social change. However, what is academia? And what is academic about the writing it produces? What do we call academic writing? The following section explores the use of the term "academic" in SWAE, drawing on Bourdieu's postulations.

\section{What is academic about academic language? Writing in academia and the accumulation of symbolic capital}

In the previous section it was shown how the communication of academic knowledge is linked to the written mode, conceptualized as the preferred mode to "communicate" and validate scientific knowledge in the current economic system. In this section, I apply Bourdieu's postulations to explore the role of "academic" discourse in today's world and how it relates to issues of hegemony and power.

As proposed in the previous section and according to Gramsci, the interplay between current structural and superstructural conditions sets writing as the preferred and legitimized mode of communicating science. Academic institutions,

\footnotetext{
${ }^{8}$ In regards to methodologies, Marxist feminist studies have shown that there exists a hegemony of the scientific method associated with the hard sciences (see Sprague, 1997).
} 
which are noncoercive institutions, therefore generate a hegemonic discourse where writing is established as the appropriate mode of communicating the academic discourse. But how is this hegemony materialized? How do these processes existing in the superstructure reinforce domination? And who is the dominated and who is the dominator in academic writing?

According to Swartz (1997), what distinguishes Bourdieu from Marxists is that he looks "into the black box of cultural processes and institutions rather than relegating them to the abstract conceptualization of superstructure" (p. 66). Bourdieu asserts that the reproduction of social inequalities is not only based on material conditions. Dominant groups in society do not only draw on material forms of capital, but also on cultural, social and symbolic resources that "help to maintain and enhance their positions in the social order" (Swartz, 1997, p. 73).

Bourdieu (1986) defines symbolic capital as "economic or political capital that is disavowed, misrecognized and thereby recognized, hence legitimate" (p. 132). Symbolic capital confers symbolic power, "a legitimating power that elicits the consent of both the dominant and the dominated" (Swartz, 1997, p. 89). Gained through symbolic struggle, symbolic power is achieved and maintained by means of symbolic violence, which is "the imposition of a cultural arbitrary by an arbitrary power" (Bourdieu \& Passeron, 1998, p. 5). The arbitrary power is constituted by a dominant class or class fraction in society that imposes a cultural arbitrary, a "definition of the social world that is best suited to their interests" (Bourdieu, 1991, p. 167). One major component of symbolic capital, symbolic power, and symbolic violence, is the "misrecognition" of their arbitrary character that brings with it the naturalization of the "selection of meanings" (Bourdieu \& Passeron, 1998, p. 8) pertaining to the dominant class. Symbolic violence, thus, facilitates the reproduction of the social order and power relations by naturalizing and conferring legitimacy on the cultural arbitrary imposed by the dominant group. According to Swartz (1997), “[m]isrecognition is tied to Bourdieu's strong claim that all actions are interested. The logic of self-interest underlying all practices-particularly those in the cultural domain-is misrecognized as a logic of 'disinterest'” (p. 90). It is by being embedded in this logic of disinterest that "activities and resources gain in symbolic power, or legitimacy" (p. 90).

Worldwide in academia, written scientific discourse is embedded with a great amount of symbolic and cultural capital that confers upon this discourse an equally great amount of symbolic power. According to Bourdieu (1991), academic discourse is a worldwide legitimate discourse that won its legitimacy "through an arbitrary relativization of the dominant usage, which is socially recognized as legitimate, and not only by those who are dominant" (p. 53). The fact that academic written discourse is broadly recognized as legitimate not only in academia but also in society in general, makes it hegemonic according to Gramsci's postulates. This hegemony is not only related to a preferred mode of communication (written) but also to a preferred variety within each language.

According to Bourdieu, academic written discourse embodies a prestigious variety of language, with a great amount of linguistic capital. This prestigious variety 
of language is nothing less than an arbitrary linguistic competence endowed with linguistic capital through a legitimating process that does not take place in isolation, but is part of the cultural field, which contains the linguistic market. The linguistic market is what endows this arbitrary written variety of language with linguistic capital, and the educational system plays a central role in the "reproduction of the market without which the social value of the linguistic competence, its capacity to function as linguistic capital, would cease to exist" (Bourdieu, 1991, p. 57).

Academic discourse, then, is a code that is "imposed and inculcated as the principle of the production and evaluation of speech" (Bourdieu, 1991, p. 61). Therefore, academic written discourse is not only constituted by a legitimate language but it also helps to constitute the legitimate language. Structuring structure, structured structure, and instrument of domination, academic discourse is a symbolic instrument.

First, as a structuring structure, academic written language is an "instrument for knowing and constructing the objective world" (Bourdieu, 1991, p. 165). It is through academic writing that scientific knowledge is constructed and communicated, and reality objectified. As a structuring structure, academic language allows the construction and communication of scientific knowledge (objectivity) that is based on the agreement between the members of the academia (subjects).

Second, as a structured structure, academic written language is a structured system that allows science to be communicated. In this sense, academic language can be conceptualized as a "pre-constructed object" (Bourdieu, 1991, p. 44) that merely allows communicating an objective meaning, in this case, scientific facts.

Third, as an instrument of domination, academic language is a source of power because it produces the "instrument of production, such as rhetorical devices, genres, legitimate styles and manners and, more generally, all the formulations destined to be 'authoritative'." Therefore, academic language "confers to those who engage in it a power over language and thereby over the ordinary users of language, as well as over their capital" (Bourdieu, 1991, p. 58). It is for this reason that academic discourse "gives to those who hold it, or who appear to hold it, a monopoly of the legitimate viewpoint, of self-fulfilling prophecy" (Bourdieu, 1988, p. 28).

Finally, these three characteristics that constitute academic discourse as a symbolic instrument do not exclude each other but constantly interact. In order to be considered as such, academic discourse has to "take into account the state of representations of scientificity and the norms to be respected in practice in order to produce scientific effect and thereby acquire symbolic efficacity and the social profits associated with conformity to scientific appearances" (Bourdieu, 1988, p. 29). Consequently, the three elements interact since academic discourse is a structured structure ("norms to be respected in practice") that has a structuring function ("scientific effect") that serves as an instrument of domination ("symbolic efficacity"). 
If we take into account the fact that writing is one of the main vehicles through which academic discourse is spread, not only nationally but internationally in today's world, the analysis of academic writing as a symbolic instrument becomes an imperative. In it we can recognize an ideal arena for the reproduction of social inequalities not only at national or local level, but also at a global level.

The way science is currently being communicated internationally establishes the research paper as the main genre of publication (Swales, 1990) and English as the legitimate language variety (Curry \& Lillis, 2004). Therefore, in the international scientific arena, an arbitrary power establishes a cultural arbitrary: SWAE as the legitimate international science language, and research paper as the preferred genre to communicate knowledge. This cultural arbitrary finds its materialization in the fact that an overwhelming number of the most renowned international academic journals publish research papers written in English (for a more detailed discussion see Canagarajah, 1996, pp. 440-441).

Therefore, the international sphere constituted mainly by academic journals can be seen as what I call "international scientific field": an international publication market oriented towards "knowledge-manufacturing" practices that are nothing less than misrecognized symbolic capital. On the other hand, there also exists what I call "national scientific fields." National scientific fields are constituted by local publication markets and writing practices that are relatively autonomous. The international sphere and the local sphere are related and, as glocalisation theories propose, each local sphere enacts the "socio-spatial power choreographies" (Swyngedouw, 2004, p. 26) in a particular way.

According to Canagarajah (1996), in those countries that belong to what Wallerstein calls the "periphery," the knowledge-construction process is different, and scholars "might develop [their] own intellectual agenda and academic cultureone that is not necessarily in step with the other circles in the discipline" (p. 443). Due to geopolitical realities related to "the prestige of the mainstream journals" mostly published in English, and "the dominance of center academic communities" (Canagarajah, 1996, p. 443), the differences between the national scientific and the international scientific fields are more noticeable in those countries that belong to the periphery. Therefore, even if we consider disciplinary fields as the thread that unites scholars internationally, national scientific fields can be seen as relatively autonomous from international scientific fields.

Despite the differences that can be drawn between the international and the national scientific fields, in Bourdieu's terms, they have something in common: each of them is a power structure in which there are different positions linked by power or domination relations. Positions are defined by capital (symbolic and economic). The kinds of capitals, the kinds of assets that are valued may vary across fields. And within fields, power results from the differences in capital among positions and agents therein that struggle to obtain and preserve capital.

In addition, the international and national fields are interwoven and related. However, since the international scientific field in each discipline rises dominant 
over the national scientific fields, the relationships between the international and national fields are not based on equality but on power differentials. In this way, the mechanisms of domination that are present in each field are replicated in a higher scale in the relationships established between the international and the national fields.

An example of these mechanisms of domination is when non-Englishspeaking scholars need to publish in SWAE. When acting in the international scientific field, these multilingual scholars seem to be dispossessed of cultural and symbolic capital since what is valued in their national scientific field is not necessarily valued in the international one. Sometimes this dispossession of cultural and symbolic capital is rooted in the lack of "legitimate" linguistic competence: SWAE. This lack, in the international scientific field, constitutes an "objective dispossession of the dominated classes," related to the "monopoly of the legitimated use of the legitimated language" (Bourdieu, 1991, p. 59), the prestige variety of SWAE as the language of science. In this way, each field determines the relative positions and dispositions of the agents that "struggle for control over valued resources" (Swartz, 1997, p. 122).

Non-English-speaking scholars, then, despite possessing symbolic and cultural capital that assigns them certain positions and dispositions in their national academic fields, lack the legitimate competence of the arbitrary language of science and "are de facto excluded from the social domains in which this competence is required, or are condemned to silence" (Bourdieu, 1991, p. 55). The international academic field, therefore, "leaves them 'speechless', 'tongue-tied', 'at a loss for words', as if they were suddenly dispossessed of their own language" (Bourdieu, 1991, p. 52). In order to avoid this and to be able to participate in the field struggle, non-English-speaking scholars should acquire a new "habitus" that would enable them to adapt and produce appropriate texts written in SWAE to gain capital in the international scientific field.

Habitus is defined by Bourdieu and Passeron (1998) as "the product of internalization of the principles of a cultural arbitrary capable of perpetuating itself after PA [pedagogic action] has ceased and thereby of perpetuating in practices the principles of the internalized arbitrary" (p. 31). Thus, there is a "symbolic violence" executed on non-English-speaking scholars when they are required to acquire those ways of expression legitimized by the dominant group. In Bourdieu's terms, these scholars, in order to enter the field, must show a "tacit acceptance of the rules of the game" (Swartz, 1997, p. 125). They must learn those "strategies" that allow them to accumulate symbolic capital. This implies the acquisition of the "mastery of the laws of the functioning of the field" (Bourdieu, 1986, p. 132) in order to succeed.

According to Mahar, Harker and Wilkes (1990), "competence and mastery of the game are analogous to a person's habitus and possession of capital as they exist within the field" (p. 7). So when non-English-speaking scholars master the standards of academic written English, they have incorporated the dominant societal representations as habitus. 
Despite the change of material conditions in the last few decades characterized by the increasing interchange between different academic communities and reflected in the growing number of international journals and conferences all over the globe, the rules of communication of science tend to preserve within them the structure of domination associated with a cultural arbitrary: SWAE. Therefore, SWAE is a symbolic instrument, a structuring structure that leads us to construct and apprehend reality according to a certain cultural arbitrary. SWAE as the "language of science," then, is not an innocuous instrument of communication that offers a common ground for interaction between the international and national scientific fields. On the contrary, it is a symbolic instrument that contributes to the preservation and reproduction of the structures of domination. These structures of domination can mute not only dominated voices, but also other epistemologies and ways of approaching social reality.

However, we can still pose the following questions: How are "competence and mastery of the game" defined in the international field? What exactly is "standard" written English in the international field? In the following section, I draw on Canagarajah's claims to problematize this term.

\section{What is standard in SWAE?}

The term "standard" is related to what is called a "monolithic" view of language. A monolithic view of language is one that points to a set of established norms or standards and to an "appropriate" use of them. It is based on the assumption that there is an ideal speaker and an ideal way of speaking, together with an ideal writer and an ideal way of writing. The ideal speaker or writer in this monolithic view of language would be an expert user, a "native" speaker or writer, who would be able to use the language according to the norms, in the correct way, and therefore, communication would be achieved through the innocuous means of a standard language.

In his writings, Canagarajah (1996, 1999, 2002a, 2002b, 2002c) contests the previous conceptualization of language, claiming that things are not that simple. Languages are not monolithic. Languages are living entities, constantly changing, and there are many varieties functioning in the real world. English, in Canagarajah's writings, becomes "Englishes" since even what it is considered "standard" English is nothing but a variety that, thanks to power dynamics, started to be seen as a universal. A fictitious universal, a fiction based on the monolithic view of language and power differentials. This universal, according to the author, is fictitious because it is just a variety that, due to politico-economic factors, became legitimized by the dominant factions of society. This correlates to the concept of cultural arbitrary proposed by Bourdieu and to the concept of hegemony proposed by Gramsci.

In academic writing, this universal, arbitrariness, or hegemony is embodied in the use of SWAE as the "language of science". Furthermore, the fictitious universal quality of SWAE is reinforced by the fact that this variety is not attached to any geographical or political boundary, since there is no country associated with it. Therefore, the monolithic view of language sets SWAE as a neutral and ideology-free 
means that allows international scientific communication. In this way, a good academic writer is a person who can enter conversations in the field because $\mathrm{s} / \mathrm{he}$ possesses the disciplinary knowledge and the ability to transmit it in SWAE. In Bourdieu's (1986) terms, an ideal writer is the one that masters "the laws of functioning in the field" (p. 132). That is, an ideal academic writer, writing in ideal SWAE.

However, what happens if this monolithic view of language is abandoned and communication is conceptualized in a more complex way? What happens if it is acknowledged that English is not a mere ideology-free system acquired by the people in order to communicate with each other? What happens if the connection between discursive practices, material conditions, and knowledge production is recognized? Opening the door to these "what ifs" is what Canagarajah (2002a, $2002 \mathrm{~b}$ ) proposes when he advocates a critical stance in scientific publication practices and English language teaching. The following section elaborates on these arguments.

\section{Abandoning a monolithic definition of SWAE}

Abandoning the monolithic view of language implies conceptualizing languages as ideologically loaded, epistemologically charged, and context-bounded. The previous does not mean that communication is unachievable, but that we should demand and value other kinds of competencies from scholars writing for an international audience. These competencies are those that multilingual speakers and writers in many parts of the world apply in their everyday life.

According to Canagarajah (2006a), multilingual speakers and writers possess communicative competence that is valuable in these globalized times since they are used to moving across and merging linguistic boundaries. In multilingual communities, then, there exists more awareness that the other's language and language variety may be different from one's own. Thus, when communicating, people make more efforts to develop competence in the other's language or language variety without considering their own as the universal one (Canagarajah, 2006a). These real discursive practices have heterogeneity as the norm and not the exception, and constantly defy the monolithic view of language. It is along these lines that Canagarajah (2006b) states that

"[t]o be really proficient in English in the postmodern world, one has to be multidialectal. Not only must we possess a repertoire of codes from the English language, we must also learn to use it in combination with other world languages. Gone are the days in which we could focus on a singular target language. These concerns gain importance as we begin to question the distinctions native/nonnative and standard/nonstandard and give due recognition to speakers of WEs [World Englishes]" (p. 26).

Proficiency in today's world is not linked to the mere mastering of standards and rules but to being able to shuttle and negotiate between languages and codes, especially when dealing with multilingual contexts such as the international 
scientific field. This anti-monolithic view of language should be the one informing scientific international communication practices where SWAE is used. This would lead to a completely different definition of "competence and mastery of the game" in Bourdieu's terms, a definition informed by a critical appraisal of how SWAE is defined.

The previous view of language is related to what has been called "English as lingua franca." Hyland (2006) explains that the term refers to

A variety of English which does not assume adherence to all anglo communication conventions and where traditional native-speakerness holds no advantages. Here academic users of English are no less proficient than native speakers of that language and they are not aspiring to speak a standard English variety. What matters is clarity and comprehensibility and L1 [first language] English speakers may need to adjust their language to new norms of international academic communication. (p. 29)

However, the author also warns the reader about conceptualizing English in a monolithic way and perceiving it as a "culture-free language" (Hyland, 2006, p. 29). In fact, the absolute opposite conception of SWAE is necessary in the international scientific field for English to be able to function as a real lingua franca, allowing a more democratic way of communicating science. The critical appraisal of SWAE offered here is what I consider to be the necessary first step towards a view of language that goes beyond this "culture-free" conception.

\section{Conclusion}

In the previous sections, I brought into consideration the structures of domination that underlay each one of the words that compose the term SWAE. I first showed how scientific communication relies on the hegemony of the written mode. The interplay between current structural and superstructural conditions set written communication as the preferred way of not only communicating science but also of validating the scientific work of authors in the current economic system. I claimed that there is a possibility for counter-hegemonic movements in academia: the use of modes of communicating science that go beyond writing would validate different scientific epistemologies and methodologies.

Second, I demonstrated that academic discourse is a structured structure ("norms to be respected in practice") that has a structuring function ("scientific effect") and that serves as an instrument of domination ("symbolic efficacity"). Thus, academic language is an arbitrarily legitimated prestigious variety, and mechanisms of domination are present in the international and national scientific fields in regards to the use of SWAE. I also claimed that these structures of domination can mute not only other forms of communication but also the construction of science, if they are not acknowledged.

Third, I explained how the previous domination structures are related to a monolithic view of language which imposes the standard in SWAE as a fictitious 
universal. This fictitious universal conceals the fact that SWAE it is just a legitimized variety. I proposed that for English to become a real lingua franca, it should be regarded as ideologically loaded, epistemologically charged, and context-bounded. In this way, scholars writing for an international audience should be able to move across and merge linguistic boundaries, having heterogeneity as the norm and not the exception.

It is my belief that the recognition of the hegemony of the written mode, the structure of domination associated with a cultural arbitrary, and the fictitious universal of a monolithic view of language is the first step towards a more democratic conceptualization of scientific communication. This democratic way of communicating science should: 1) acknowledge the intrinsic connection between different modes of communicating science and knowledge-construction practices, and open the door to nonhegemonic modes of communication; 2) recognize the power structures that operate in the national and international scientific fields; 3 ) envision academic discourse as a social construction and recognize that even disciplinary fields are constructed ${ }^{9}$ and thus are open for change; 3 ) dismantle the monolithic view of language and go beyond the native/non-native or standard/nonstandard categories, defying the hegemonic aspect of SWAE in order to allow real growth and communication in science.

The critical appraisal of SWAE offered in this paper disentangled the power structures present in the current modes of construction and communication of scientific knowledge. This, I believe, is the first step for achieving more democratic practices when communicating science. Science communication and production should give place to many still unheard voices. This would not only benefit those who have not been heard yet, but it would also promote a more democratic production and spread of scientific knowledge.

\section{References}

Bourdieu, P. (1986). The production of belief: Contribution to an economy of symbolic goods. (R. Nice, Trans.). In R. Collons et al. (Eds.), Media, culture and society (pp. 131-163). London: Sage.

Bourdieu, P. (1988). Homo academicus. (P. Collier, Trans.). Palo Alto, CA: Stanford University Press.

Bourdieu, P. (1991). Language and symbolic power. (G. Raymond \& M. Adamson, Trans.). Cambridge, MA: Harvard University Press.

Bourdieu, P., \& Passeron, J. C. (1998). Reproduction in education, society and culture (2nd. ed.). (R. Nice, Trans.). London: Sage.

\footnotetext{
${ }_{9}^{9}$ In this regard, Lenoir (1993) offers an interesting description of disciplinary and research programs as discursive productions.
} 
Burke, B. $(1999,2005)$ Antonio Gramsci, schooling and education. In The encyclopedia of informal education. Retrieved from http://www.infed.org/thinkers/et-gram.htm

Buta, J., \& Sued, G. (2005, August). Publicaciones científicas en internet: Relaciones entre lo local y lo global. Symposium conducted by Sociedad Argentina de Informática e Investigación, Rosario, Argentina.

Canagarajah, S. (1996). "Nondiscursive" requirements in academic publishing, material resources of periphery scholars, and the politics of knowledge production. Written Communication, 13(4), 435-472.

Canagarajah, S. (1999). Resisting linguistic imperialism in English teaching. New York: Oxford University Press.

Canagarajah, S. (2002a). Critical academic writing and multilingual students. Ann Arbor: University of Michigan Press.

Canagarajah, S. (2002b). A geopolitics of academic writing. Pittsburgh, PA: University of Pittsburgh Press.

Canagarajah, S. (2002c). Multilingual writers and the academic community: Towards a critical relationship. Journal of English for Academic Purposes, 1, 29-44.

Canagarajah, S. (2006a). The place of world Englishes in composition: Pluralization continued. College Composition and Communication, 57(4), 586-619.

Canagarajah, S. (2006b). TESOL at forty: What are the issues? TESOL Quarterly 40(1), 9-34.

Čmejrková, S. (1996). Academic writing in Czech and English. In E. Ventola \& A. Mauranen (Eds.), Academic writing: Intercultural and textual issues (pp. 137152). Philadelphia: John Benjamins.

Curry, M. J., \& Lillis, T. (2004). Multilingual scholars and the imperative to publish in English: Negotiating interests, demands, and rewards. TESOL Quarterly, 38(4), 663-688.

Forgacs, D. (Ed.). (1988). The Gramsci reader: Selected writings 1916-1935. New York: New York University Press.

Hyland, K. (2006). English for academic purposes: An advanced resource book. New York: Routledge.

Lenoir, T. (1993). The discipline of nature and the nature of disciplines. In E. MesserDavidow, D. Shumway \& D. Sylvan (Eds.), Knowledges: Historical and critical studies in disciplinarity. Charlottesville: University Press of Virginia.

Mahar, C., Harker, R., \& Wilkes, C. (1990). An introduction to the work of Pierre Bourdieu. New York: Saint Martins. 
Martín-Martín, P. (2003). A genre analysis of English and Spanish research paper abstracts in experimental social sciences. English for Specific Purposes, 22, 2543.

Mauranen, A. (1996). Discourse competence: Evidence from thematic development in native and non-native texts. In E. Ventola \& A. Mauranen (Eds.), Academic writing: Intercultural and textual issues (pp. 195-230). Philadelphia: John Benjamins.

Pennycook, A. (2001). English in the world/The world in English. In A. Burns \& C. Coffin (Eds.), Analysing English in a global context: A reader (pp. 78-92). New York: Routledge.

Reichelt, M. (2001). A critical review of foreign language writing research on pedagogical approaches. The Modern Language Journal, 85(4), 578-598.

Sprague, J. (1997). Holy men and big guns: The Can[n] on in social theory. Gender and Society, 11(1), 88-107.

Swales, J. (1990). Genre analysis: English in academic and research settings. Cambridge, MA: Cambridge University Press.

Swales, J., \& Feak, C. (2003). Academic writing for graduate students: Essential tasks and skills (3rd ed.). Ann Arbor: University of Michigan Press.

Swartz, D. (1997). Culture and power: The sociology of Pierre Bourdieu. Chicago: The University of Chicago Press.

Swyngedouw, E. (2004). Globalisation or 'glocalisation'? Networks, territories and rescaling. Cambridge Review of International Affairs, 17(1), 25-48.

Ventola, E., \& Mauranen, A. (Eds.). (1996). Academic writing: Intercultural and textual issues. Philadelphia: John Benjamins.

Wysocki, A. F. (2004). Opening new media to writing: Openings and justifications. In A. F. Wysocki, J. Johnson-Eilola, C. Selfe \& J. Sirc (Eds.), Writing new media: Theory and applications for expanding the teaching of composition. Logan: Utah State University Press. 